\title{
Secretin and Vasoactive Intestinal Peptide Activate Tyrosine Hydroxylase in Sympathetic Nerve Endings
}

\author{
Michael A. Schwarzschild and Richard E. Zigmond \\ Department of Biological Chemistry and Molecular Pharmacology, Harvard Medical School, Boston, Massachusetts 02115
}

\begin{abstract}
Secretin and vasoactive intestinal peptide (VIP) are known to stimulate tyrosine hydroxylase (TH) activity acutely in the rat superior cervical ganglion (SCG). Because TH-containing neurons in the SCG innervate the iris, submaxillary gland, and pineal gland, we examined the effects of secretin and VIP in these 3 autonomic end organs in vitro. Both peptides stimulated TH activity in each tissue. These stimulations resembled those in the SCG in that (1) secretin displayed a higher potency than VIP in all 3 end organs, (2) the peptide effects were unchanged when calcium was excluded from the incubation medium, and (3) they were mimicked by activators of the cyclic adenosine monophosphate (cAMP) pathway. These findings indicate that secretin and VIP can regulate transmitter metabolism in both the cell bodies and axon terminals of neurons originating in the SCG. Furthermore, the data raise the possibility that catecholamine synthesis in sympathetic nerve terminals is modulated by peptides released by other, nearby nerve endings.
\end{abstract}

Neural and humoral factors regulate the rate of neurotransmitter synthesis in several neuronal systems. In many cases, this regulation is thought to represent an adaptation by which the rate of transmitter synthesis is altered to compensate for changes in the rate of transmitter release (Thoenen et al., 1979; El Mestikawy et al., 1981; Tuček, 1985; Zigmond, 1985; Birch and Fillenz, 1986a, b). In the rat superior cervical ganglion (SCG), cholinergic agonists and certain neuropeptides acutely stimulate the activity of tyrosine hydroxylase (TH) (Zigmond, 1985), the enzyme that catalyzes the rate-limiting step in the biosynthesis of norepinephrine (Levitt et al., 1965). These neuropeptides are all members of the secretin-glucagon family and include secretin and vasoactive intestinal peptide (VIP).

The SCG contains the cell bodies and dendrites of adrenergic neurons whose terminals are found in various autonomic end organs, including the iris, the salivary glands, and the pineal gland (Skok, 1973; Bowers et al., 1984). Since these terminals

Received Jan. 21, 1988; revised May 18, 1988; accepted May 26, 1988.

This research was supported by United States Public Health Services (Grant NS 12651). M.A.S. was supported by a predoctoral training grant (GM07306) from NIH, and R.E.Z. was supported by a Research Scientist Development Award (MH00162) from NIMH. We thank the members of Dr. John Maggio's laboratory, particularly Dr. Phon Too, for providing advice and equipment to analyze VIP degradation, Drs. Jean Rivier and Wiley Vale for the gift of hGRF(1-29) $\mathrm{NH}_{2}$, and Drs. Story Landis and Agnes Schonbrunn for their helpful comments on the manuscript.

Correspondence should be addressed to Dr. Richard E. Zigmond, Department of Biological Chemistry and Molecular Biology, Harvard Medical School, 250 Longwood Avenue, Boston, MA 02115.

Copyright (C) 1989 Society for Neuroscience $0270-6474 / 89 / 010160-07 \$ 02.00 / 0$ are important sites of transmitter synthesis and release by sympathetic neurons, we have examined whether secretin and VIP also regulate $\mathrm{TH}$ activity in these 3 end organs.

\section{Materials and Methods}

In situ $T H$ assay. Male Sprague-Dawley rats (100-200 gm) were killed using a cervical dislocator (Melron, Inc.), for submaxillary glands, or by decapitation, for irises and pineal glands. Submaxillary glands, eyeballs, or pineal glands were excised and placed in Earle's balanced salt solution gassed with $5 \% \mathrm{CO}_{2} / 95 \% \mathrm{O}_{2}$ (EBSS; Gibco Laboratories) at $4^{\circ} \mathrm{C}$. Superficial connective tissue and adjacent sublingual glands were dissected from submaxillary glands. Each submaxillary gland was then cut perpendicular to its long axis with 9 single-edged industrial razor blades (0.009 inch thickness, VWR) bonded together in parallel, yielding 8 slices $(0.9 \mathrm{~mm}$ thick). Irises were dissected from eyeballs just medial to the ciliary body. Adherent connective tissue was dissected from pineal glands and their stalks were cut off close to the body of the gland. Tissues were washed for approximately $1 \mathrm{hr}$ at $4^{\circ} \mathrm{C}$ with 2 changes of EBSS ( 1 $\mathrm{ml}$ for each slice or organ).

Tissues were preincubated in EBSS ( $2 \mathrm{ml}$ for each slice or organ) at $37^{\circ} \mathrm{C}$ for $30 \mathrm{~min}(2 \times 15 \mathrm{~min}$ with fresh medium). Tissues were next incubated individually in $600 \mu \mathrm{l}$ EBSS with $30 \mu \mathrm{M}$ brocresine (Lederle Laboratories), an inhibitor of Dopa decarboxylase, and $0.1 \mathrm{~mm}$ EDTA at $37^{\circ} \mathrm{C}$ for $10 \mathrm{~min}$ (unless otherwise noted). Dopa accumulation was found to be optimal in submaxillary gland slices between 15 and $50 \mu \mathrm{M}$ brocresine and dropped off sharply above $150 \mu \mathrm{M}$ (data not shown). In all experiments, except the time course (see legend to Fig. 1), some tissues were also incubated for $10 \mathrm{~min}$ without brocresine. The amount of Dopa measured in these tissues and their media typically represented one-fourth to one-third the amount of Dopa measured after the $10 \mathrm{~min}$ incubation with brocresine and was subtracted from the latter value to calculate the quantity of Dopa accumulated. Although the source of the Dopa observed in the absence of brocresine is not known, the amount of this Dopa decreased dramatically in all 3 tissues following removal of the SCG (data not shown). This Dopa content was not affected by incubating submaxillary slices with $10 \mu \mathrm{M}$ secretin (i.e., without brocresine; data not shown).

Incubations were stopped by placing the medium on ice and transferring the tissue to $200 \mu \mathrm{l}$ of $150 \mathrm{~mm}$ trichloroacetic acid with $0.1 \mathrm{mM}$ EDTA and 10 pmol epinephrine (an internal standard) at $4^{\circ} \mathrm{C}$. The tissue was homogenized, and its precipitate was pelleted and saved for protein determination (Lowry et al., 1951). The supernatant fluid was then combined with its corresponding incubation medium (except in the case of the time course; see legend to Fig. 1). The catecholamines present were adsorbed onto alumina, eluted with acid, separated by reversephase high-performance liquid chromatography (HPLC) and quantified electrochemically (Rittenhouse et al., 1988). A Coulochem controller (ESA model 5100A) was used, with 1 electrode in a conditioning cell (ESA model 5021) and 2 in an analytical cell (ESA model 5011) set in series at $+0.36,+0.03$, and $-0.38 \mathrm{~V}$, respectively, relative to internal reference electrodes. Under these HPLC and electrochemical conditions, $5 \mathrm{fmol}$ Dopa yielded a 5:1 signal-to-noise ratio.

Initial experiments showed that under the in situ assay conditions just described, VIP $(10 \mu \mathrm{M})$ produced no effect on Dopa synthesis in slices of the submaxillary gland (data not shown). However, measurements of VIP in the medium by reverse-phase HPLC with ultraviolet $(214 \mathrm{~nm})$ spectrophotometry revealed a dramatic decrease in its concentration (see below). Rat submaxillary glands contain high levels of 
kallikrein protease activity (Bhoola and Dorey, 1971), and VIP is susceptible to degradation by a kallikrein (Mutt and Said, 1974). Therefore, a kallikrein inhibitor, aprotinin (Boehringer Mannheim Biochemicals), was tested for its ability to prevent VIP loss in 5 experiments. When submaxillary gland slices were prepared, preincubated, and incubated as described above, except that the incubation medium also contained VIP $(10 \mu \mathrm{M})$ and BSA $(1 \mathrm{mg} / \mathrm{ml})$, the VIP concentration decreased by an average of $72 \%$ over the $10 \mathrm{~min}$ incubation. When aprotinin [500 kallikrein inhibitor units (KIU)/ml] was also included in the medium, the VIP concentration decreased by an average of $49 \%$. Since VIP content was assessed only in the medium surrounding the slice, the decreases in peptide concentration may have been greater within the slice. Although the extent of the decreases varied considerably between the experiments, aprotinin significantly reduced the loss of VIP in each of them $(p<0.05)$. Therefore, aprotinin $(500 \mathrm{KIU} / \mathrm{ml})$ was included in the medium in experiments on submaxillary gland slices both for the last $15 \mathrm{~min}$ of the preincubation period and during the incubation with peptides.

In vitro $T H$ assay. Irises and pineal glands were dissected, preincubated, and incubated as described above, except that brocresine and ED'TA were excluded from the incubation medium. Following the 10 min incubation, each iris or pineal gland was homogenized at $4^{\circ} \mathrm{C}$ in 140 or $120 \mu$, respectively, of $10 \mathrm{~mm}$ potassium phosphate, $5 \mathrm{~mm}$ sodium pyrophosphate, $0.1 \%$ Triton $\mathrm{X}-100, \mathrm{pH} 7.2$. A $50 \mu \mathrm{l}$ aliquot was then incubated for $6 \mathrm{~min}$ at $37^{\circ} \mathrm{C}$ in a final volume of $100 \mu 1$ containing $200 \mathrm{mM}$ potassium phosphate, $30 \mu \mathrm{M}$ 6-methyl-tetrahydropterin, $80 \mu \mathrm{M}$ L-tyrosine, $300 \mu \mathrm{M}$ brocresine, $40 \mathrm{~mm} \beta$-mercaptoethanol, and $10^{5}$ units $/ \mathrm{ml}$ catalase, $\mathrm{pH} 7.0$. The incubation was stopped by returning the samples to $4^{\circ} \mathrm{C}$ and adding $1 \mathrm{ml}$ of chilled $0.5 \mathrm{M}$ Tris, $\mathrm{pH}$ 8.6, with $0.1 \mathrm{~mm}$ EDTA and 5 pmol epinephrine (an internal standard). Dopa was then extracted with alumina and measured by HPLC with electrochemical detection, as described above. Aliquots of homogenate were also assayed for protein content (Lowry et al., 1951). The basal activity in iris homogenates was $0.6 \mathrm{pmol} \mathrm{Dopa} / \mathrm{mg}$ protein min.

Statistical methods. All numerical values are presented as means \pm SEM. The statistical significance of differences was assessed by Student's $t$ test for 2 means (2-tailed).

\section{Results and Discussion}

\section{Measurements of TH activity}

Noradrenergic neurons contribute far more to the mass of sympathetic ganglia than to the mass of the end organs they innervate. Not surprisingly then, the specific enzymatic activity of $\mathrm{TH}$ in the SCG greatly exceeds that in its end organs (e.g., Dornay et al., 1985). Thus, direct measurement of TH activity in end organs has generally relied on in vitro determinations at saturating concentrations of substrate and cofactor and at an optimal, but unphysiological, $\mathrm{pH}$. To study the acute regulation of end-organ $\mathrm{TH}$ activity in a relatively physiological environment (i.e., in intact nerve terminals), we have adapted an in situ TH assay that we previously used in studies on the SCG (Ip et al., 1982b). In this assay, Dopa, the product of the reaction catalyzed by $\mathrm{TH}$, builds up in ganglia incubated with the Dopa decarboxylase inhibitor brocresine. The sensitivity of the assay was enhanced by a high-efficiency amperometric system for the electrochemical detection of Dopa (Kilpatrick et al., 1986).

Several findings validate this assay as a measure of in situ TH activity in the iris and the submaxillary gland slice. First, both of these tissues accumulated Dopa linearly with time for at least $25 \mathrm{~min}$ in the presence of brocresine (Fig. 1; data not shown for the iris). For the submaxillary slice, Dopa accumulation was measured separately in the tissue and its medium. Initially, more Dopa appeared in the slice than in the medium. By $15 \mathrm{~min}$ of incubation, however, Dopa accumulation in the slice had slowed and was exceeded by that in the medium. These time courses suggest that Dopa is formed in the tissue and then diffuses into the medium.

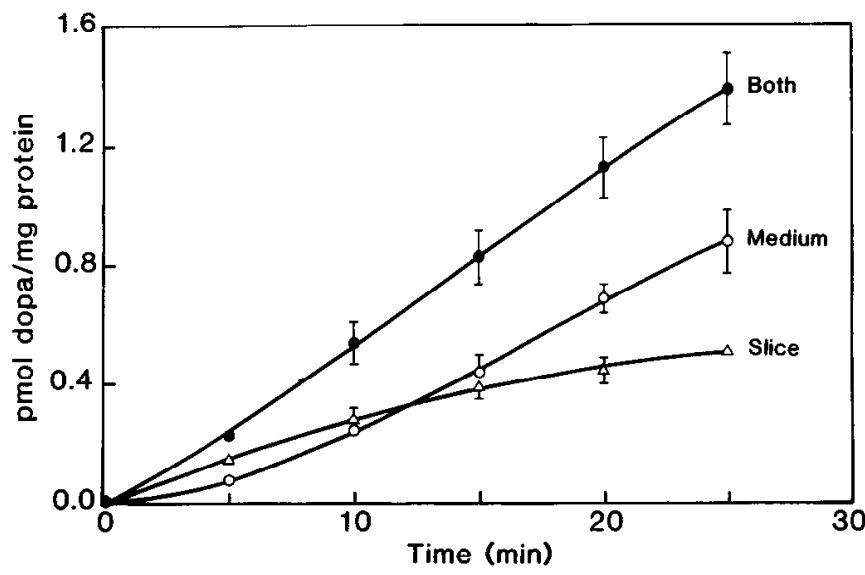

Figure 1. Time course of Dopa accumulation in slices of the submaxillary gland. Slices were incubated individually in the presence of brocresine and EDTA for $0,5,10,15,20$, or 25 min. Each incubation was terminated by transferring the slice to a tube containing $200 \mu$ l of 150 mM TCA with $0.1 \mathrm{~mm}$ EDTA and 10 pmol epinephrine, and adding $200 \mu \mathrm{l}$ of the same solution to the medium. Following homogenization of the slices, catecholamines in the TCA extracts of the slices and in the acidified media were measured as described in Materials and Methods. Slices "incubated" for 0 min with brocresine contained $0.11 \pm$ $0.01 \mathrm{pmol} \mathrm{Dopa} / \mathrm{mg}$ protein, and this value was subtracted from the Dopa content of each slice to determine its brocresine-induced Dopa accumulation. The Dopa accumulation for slices (open triangles) was added to the Dopa content of the corresponding media samples (open circles) to determine their combined Dopa accumulation (filled circles). All data points represent the mean values for 4 or 5 submaxillary gland slices. Error bars in this and subsequent figures indicate SEM. For symbols without error bars, the SEM is smaller than the size of the symbol.

Second, $\alpha$-methyl- $\rho$-tyrosine ( $\alpha \mathrm{MT}$ ), a specific inhibitor of $\mathrm{TH}$, completely blocked Dopa accumulation in both the iris and the submaxillary gland in the presence or absence of secretin (Fig. 2; data not shown for the submaxillary slice).

Third, the Dopa that accumulated during the standard incubation of each tissue appeared stable (Fig. 2; data not shown for the submaxillary slice). The Dopa content of irises incubated with or without secretin for 10 min was not significantly reduced after further Dopa production was blocked by $\alpha \mathrm{MT}$ for 10 more min. Dopa accumulation represents the balance between the synthesis and the degradation of Dopa. For both tissues, the stability of Dopa in the presence of brocresine indicates that Dopa degradation is negligible and, therefore, that the rate of Dopa accumulation equals the rate of Dopa synthesis.

Fourth, bilateral removal of the SCG $2 \mathrm{~d}$ prior to the assay reduced Dopa accumulation, as well as the norepinephrine (NE) content, in the iris and the submaxillary gland slice by more than $96 \%$ (Table 1). In the iris, TH-like immunoreactivity is seen only in a dense meshwork of fibers, and ganglionectomy dramatically reduces this immunoreactivity (Björklund et al., 1985b). These observations suggest that the Dopa accumulated in the 2 tissues is produced primarily, if not exclusively, within the axon terminal regions of sympathetic neurons originating in or passing through the SCG. Together, all the above findings demonstrate that brocresine-induced Dopa accumulation in the iris and the submaxillary gland slice represents Dopa synthesis located within sympathetic nerve endings and catalyzed by $\mathrm{TH}$.

In addition to measuring Dopa synthesis in situ, TH activity was also measured in vitro in homogenates of the iris or pineal gland at $\mathrm{pH} 7.0$ in the presence of a subsaturating concentration of the cofactor, 6-methyl-tetrahydropterin $(30 \mu \mathrm{M})$. TH activity 


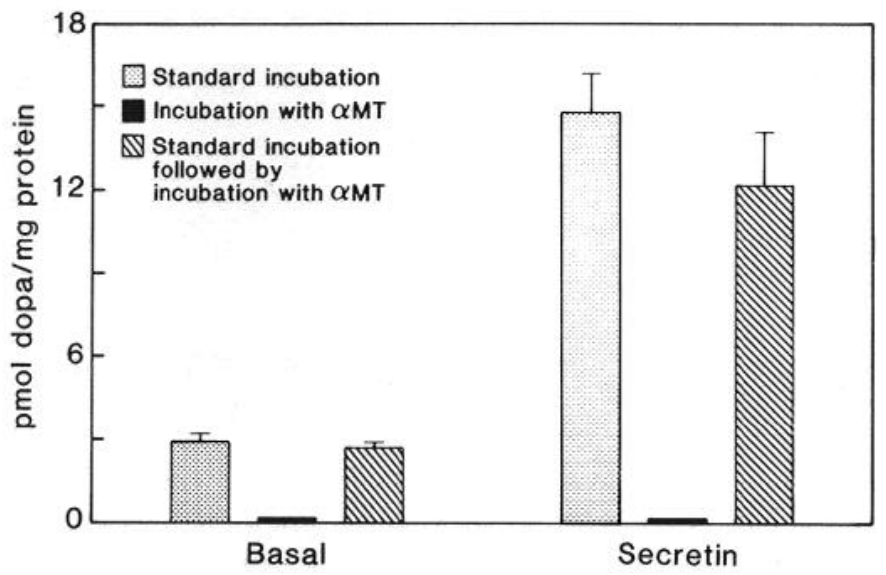

Figure 2. The effect of $\alpha \mathrm{MT}$ and the stability of accumulated Dopa in the iris. Basal and secretin-stimulated Dopa accumulations were measured in the iris during the standard $10 \mathrm{~min}$ incubation in the absence (stippled bars) or presence (solid bars) of $0.2 \mathrm{~mm} \alpha \mathrm{MT}$. At the end of the standard incubation, $20 \mu \mathrm{l}$ of $6 \mathrm{~mm} \alpha \mathrm{MT}$ was added to the media of some irises, yielding a final $\alpha \mathrm{MT}$ concentration of $0.2 \mathrm{mM}$, and the incubation was continued for $10 \mathrm{~min}$ (hatched bars). The standard incubation medium contained brocresine and EDTA $\pm 1 \mu \mathrm{M}$ secretin. No Dopa accumulated in the presence of $\alpha$ MT (with or without secretin) and the solid bars (representing 4 or 7 irises, respectively) indicate this result. All other bar heights represent the mean values for 4-8 irises.

was not measured in vitro in homogenates of submaxillary slices because of a nonlinear time course (A. R. Rittenhouse and R. E. Zigmond, unpublished observations), perhaps due to the large amount of protease released by homogenization. The activities measured by these 2 methods will be referred to as "Dopa synthesis in situ" and "TH activity in homogenates," respectively.

Preliminary studies indicated that, in the pineal gland, the homogenate assay for TH activity is a more specific measure of the catecholamine-synthesizing capacity of sympathetic nerve terminals than is the in situ assay. The pineal gland, unlike the iris and the submaxillary gland slice, lost only $22 \%$ of its Dopaaccumulating activity following bilateral removal of the SCG. This ganglionectomy, however, reduced the NE content of the pineal gland by $>99 \%$ (Table 1). This discrepancy implicates a nonsympathetic source of Dopa production within the intact pineal gland. On the other hand, when TH activity was measured in pineal homogenates at $\mathrm{pH} 7.0$ in the presence of exogenous pterin cofactor ( $30 \mu \mathrm{M})$, enzyme activity was reduced by $85 \%$ following bilateral ganglionectomy (data not shown).
Therefore, the homogenate assay was employed to study the regulation of $\mathrm{TH}$ activity in nerve terminals in the pineal gland.

\section{Peptidergic stimulation of TH activity}

Both secretin and VIP stimulated Dopa synthesis in situ in the intact iris, each producing a 4-fold maximal effect (Fig. 3B). Secretin, however, was considerably more potent than VIP. The $\mathrm{EC}_{50}$ of the former was approximately $30 \mathrm{~nm}$, while that of the latter was about $1 \mu \mathrm{M}$. Incubation of rat irises with either $10 \mu \mathrm{M}$ secretin or $10 \mu \mathrm{M}$ VIP also led to an increase in TH activity measured subsequently in tissue homogenates (2.7- or 2.1-fold, respectively; $p<0.001$ for each peptide). This stimulation of $\mathrm{TH}$ activity in homogenates suggests that the increased Dopa synthesis observed in situ reflects an activation of the enzyme, rather than simply an increase in substrate or cofactor availability or a decrease in feedback inhibition of TH by endogenous catecholamines.

In the submaxillary gland slice, the effects of secretin and VIP on Dopa synthesis in situ were measured in the presence of the kallikrein protease inhibitor, aprotinin, to reduce peptide degradation (see Materials and Methods). Secretin produced a 4-fold maximal stimulation with an $\mathrm{EC}_{50}$ of $100 \mathrm{~nm}$ (Fig. $3 C$ ). VIP (10 $\mu \mathrm{M})$ produced a 1.5-fold stimulation of Dopa synthesis $(p<$ 0.05 ; Fig. $3 C$ ). While secretin displays a greater potency than VIP in both the submaxillary gland slice and the iris, the potency of each peptide is lower in the former tissue than in the latter. The difference between these tissues may reflect an incomplete blockade of kallikrein activity by $500 \mathrm{KIU} / \mathrm{ml}$ aprotinin and/ or the action of an aprotinin-resistant protease(s) released or exposed in slices of rat submaxillary gland. Alternatively, the difference may reflect different receptor affinities in the 2 tissues.

Two other members of the secretin-glucagon family of peptides were also tested for an effect on submaxillary TH activity in the presence of aprotinin. Peptide histidine isoleucine amide (PHI) is encoded by the same rat cDNA as is VIP (Nishizawa et al., 1985) and has been found to be colocalized with VIP in many regions of the nervous system (Fahrenkrug et al., 1985). PHI $(10 \mu \mathrm{M})$ increased Dopa synthesis in the submaxillary slice 1.7-fold ( $30 \pm 5$ and $52 \pm 3 \mathrm{fmol} \mathrm{Dopa} / \mathrm{mg}$ protein $/ \mathrm{min}$ for control and peptide-treated groups, respectively). In the same experiment, the $\mathrm{N}$-terminal amidated fragment of human growth hormone-releasing factor hGRF $(1-29) \mathrm{NH}_{2}(10 \mu \mathrm{M})$ did not alter Dopa synthesis $(29 \pm 2 \mathrm{fmol} \mathrm{Dopa} / \mathrm{mg}$ protein $/ \mathrm{min})$. The lack of effect of hGRF(1-29) $\mathrm{NH}_{2}$ in the submaxillary gland demonstrates the specificity of the peptidergic stimulation of $\mathrm{TH}$ activity.

Table 1. Effects of ganglionectomy on Dopa accumulation and NE content in end organs of the SCG

\begin{tabular}{|c|c|c|c|c|}
\hline \multirow[b]{2}{*}{ Tissue } & \multicolumn{2}{|c|}{$\begin{array}{l}\text { Dopa accumulation } \\
\text { (pmol/mg protein } / \mathrm{min})\end{array}$} & \multicolumn{2}{|c|}{$\begin{array}{l}\text { NE content } \\
\text { (pmol/mg protein) }\end{array}$} \\
\hline & Sham & SCG-X ${ }^{a}$ & Sham & SCG-X $\mathrm{X}^{a}$ \\
\hline Iris & $0.14 \pm 0.05$ & $<0.005$ & $281 \pm 23$ & $<12$ \\
\hline Submaxillary slice & $0.029 \pm 0.004$ & $<0.001$ & $68 \pm 5$ & $<1$ \\
\hline Pineal gland ${ }^{b}$ & $4.9 \pm 0.2$ & $3.8 \pm 0.3$ & $285 \pm 19$ & $<4$ \\
\hline
\end{tabular}

${ }^{\circ}$ SCG-X refers to animals in which both SCG were removed $2 \mathrm{~d}$ before Dopa accumulation was measured.

${ }^{b}$ Pineal glands were incubated for only 2 min because the time course for Dopa accumulation in the pineal gland was linear for less than $6 \mathrm{~min}$ (data not shown). 

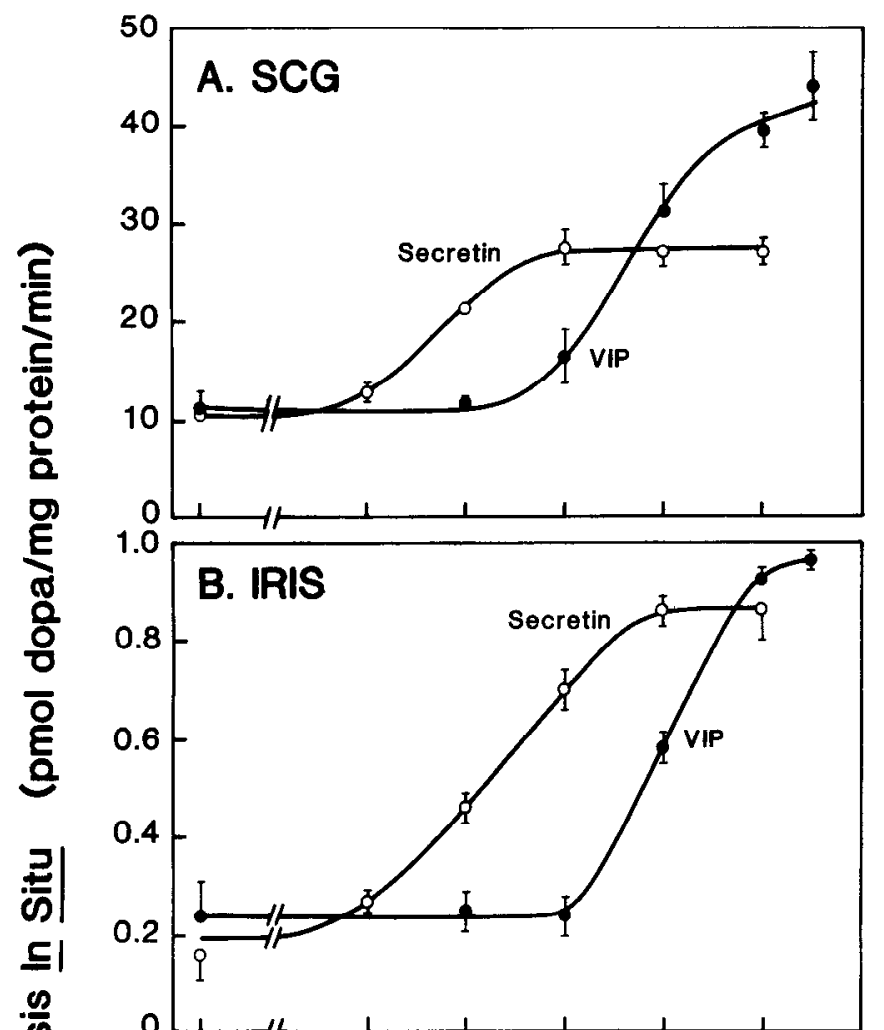

क

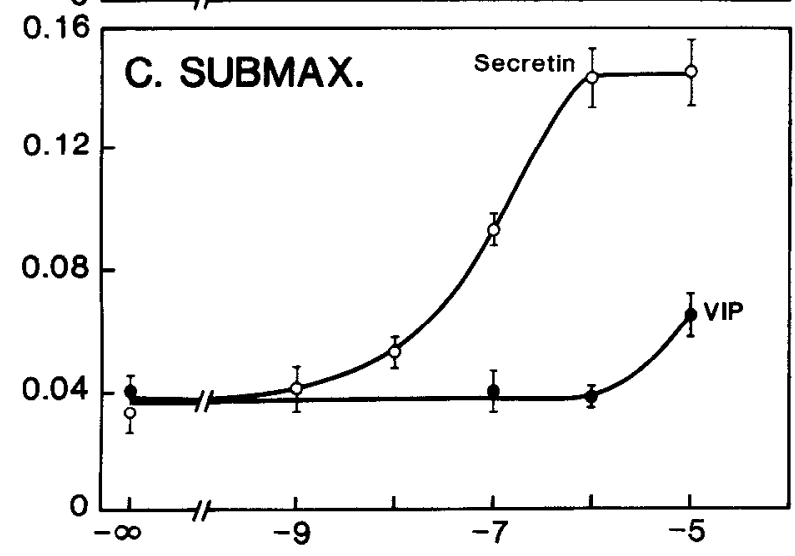

[Peptide] $(\log M)$

Figure 3. Peptidergic stimulation of Dopa synthesis in situ in the SCG and in 2 of its end organs. Concentration-response relationships were determined for secretin (open circles) and VIP (filled circles) in the iris and submaxillary gland slice and compared with those in the SCG. $A$, Replotted from Ip et al. (1982a). SCG were incubated for $15 \mathrm{~min}$ in the presence of $0.1 \mathrm{~mm}$ L-tyrosine, $150 \mu \mathrm{M}$ brocresine, $1 \mathrm{mg} / \mathrm{ml} \mathrm{BSA}$, and $0.1 \mathrm{~mm}$ EDTA. $B$, Whole rat irises were incubated for $10 \mathrm{~min}$ in the presence of $30 \mu \mathrm{M}$ brocresine, EDTA, $1 \mathrm{mg} / \mathrm{ml} \mathrm{BSA}$, and various concentrations of secretin (Peninsula Laboratories) or VIP (Bachem Inc.). $C$, Rat submaxillary gland slices were incubated as in $B$ except that aprotinin was included. All data points represent mean values from at least 4 ganglia, 4 irises, or 4 submaxillary gland slices.

In the pineal gland, secretin produced a 2-fold maximal stimulation of $\mathrm{TH}$ activity in homogenates, with an $\mathrm{EC}_{50}$ of approximately $20 \mathrm{~nm}$ (Fig. 4). VIP produced 1.4- and 1.8 -fold stimulations of $\mathrm{TH}$ activity in the pineal gland at concentrations of 10 and $30 \mu \mathrm{M}$, respectively $(p<0.05$ and $p<0.001$, respectively).

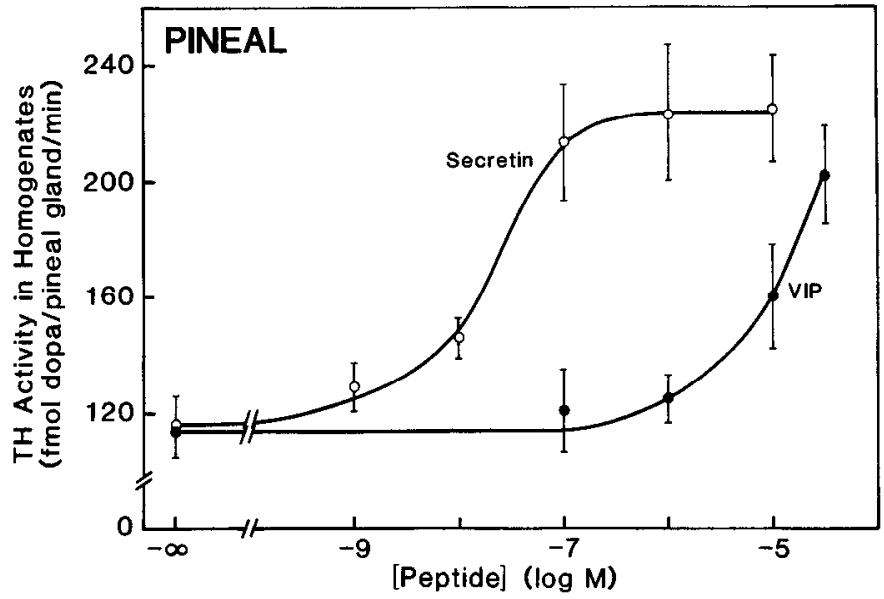

Figure 4. Peptidergic stimulation of TH activity in homogenates of the pineal gland. Concentration-response relationships were determined for secretin (open circles) and VIP (filled circles) in the pineal gland. The incubation medium contained aprotinin, $1 \mathrm{mg} / \mathrm{ml} \mathrm{BSA}$, and various concentrations of secretin or VIP. All data points represent mean values for 5-9 pineal glands.

\section{Calcium independence of peptidergic stimulation}

These peptide effects and their concentration-response relationships in the iris, submaxillary gland slice, and pineal gland are similar to those previously reported by this laboratory for the SCG [Fig. 3A, Ip et al., 1982a; see Ip et al., 1984, for PHI data; see Schwarzschild et al., 1985, for hGRF(1-29) $\mathrm{NH}_{2}$ data]. Together the data raise the possibility that secretin and VIP act directly on sympathetic neurons through a receptor or set of receptors found both on the cell bodies and axon terminals of sympathetic neurons. In support of a direct peptidergic effect on postganglionic sympathetic neurons in the SCG, Ip and colleagues found that the increases in Dopa synthesis in situ produced by secretin and VIP in the SCG were not dependent on external calcium (Ip et al., 1985) or on the presence of preganglionic nerve terminals (Ip et al., 1982a).

Whether these peptides also act directly on sympathetic nerve terminals is of interest. VIP is known to affect the release of several substances from nerve terminals and target cells in autonomic end organs and thus could produce its effect on $\mathrm{TH}$ activity indirectly. For example, VIP stimulates release of ACh from myenteric neurons in the small intestine (Yau et al., 1986) and of catecholamines from adrenal medulla (Malhotra and Wakade, 1987), and enhances the muscarinic stimulation of salivary secretion (Lundberg, 1981). In each case, the release process is dependent on extracellular calcium (Douglas and Poisner, 1963; Yau et al., 1986; Malhotra and Wakade, 1987). Therefore, we tested the calcium dependency of the peptidergic stimulation of Dopa synthesis in situ in end organs.

Excluding calcium from the medium did not alter the control rate of Dopa synthesis in the submaxillary slicc or the ability of secretin to increase this rate (Fig. 5). In the same experiment, the increase in the rate of Dopa synthesis produced by a different stimulant, $55 \mathrm{~mm}$ potassium, was abolished in medium without added calcium. The stimulatory effect of VIP on submaxillary Dopa synthesis was also unaffected by leaving calcium out of the incubation medium. Thus, a 1.6-fold increase in Dopa synthesis was produced by $10 \mu_{\mathrm{M}}$ VIP in standard medium $(p<$ $0.05 ; 20 \pm 2$ and $32 \pm 4 \mathrm{fmol} \mathrm{Dopa} / \mathrm{mg}$ protein $/ \mathrm{min}$ for control 


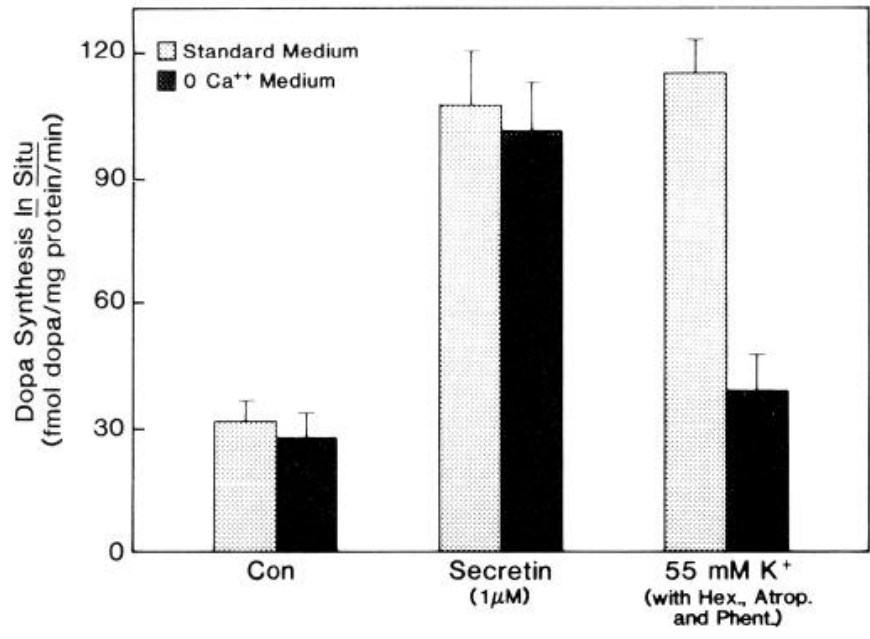

Figure 5. Calcium dependence of secretin-stimulated Dopa synthesis. Stimulations of Dopa synthesis in submaxillary slices by secretin and by elevated potassium were assessed in the presence or absence of extracellular calcium. All incubation media contained brocresine, $0.1 \mathrm{~mm}$ EDTA, and $1 \mathrm{mg} / \mathrm{ml} \mathrm{BSA}$. Calcium-free medium (dark bars) contained no calcium and $2.6 \mathrm{~mm}$ magnesium, whereas the standard medium (light bars) contained $1.8 \mathrm{~mm}$ calcium and $0.8 \mathrm{~mm}$ magnesium. High- $\mathrm{K}^{+}$ media contained $55 \mathrm{~mm} \mathrm{KCl}$ and $66 \mathrm{~mm} \mathrm{NaCl}$, whereas the standard medium contained $5 \mathrm{~mm} \mathrm{KCl}$ and $116 \mathrm{~mm} \mathrm{NaCl}$. In addition, high- $\mathrm{K}^{+}$ medium contained the cholinergic antagonists hexamethonium ( $3 \mathrm{~mm})$ and atropine $(6 \mu \mathrm{M})$ and the adrenergic antagonist phentolamine (10 $\mu \mathrm{M})$. These antagonists were included to eliminate a possible indirect effect of elevated potassium on sympathetic nerve terminals, mediated by the release of ACh or norepinephrine and the stimulation of presynaptic nicotinic, muscarinic, or $\alpha$-adrenergic receptors. In standard medium, the 3 antagonists, tested together, had no effect on Dopa synthesis (data not shown). Slices incubated without calcium or with the 3 antagonists were also preincubated under those conditions for the last $15 \mathrm{~min}$ of the preincubation. Each value represents the mean for 4 submaxillary gland slices.

and VIP groups, respectively) and a 1.8-fold increase in medium without added calcium $(p<0.001 ; 22 \pm 2$ and $39 \pm 3$ for control and VIP groups, respectively). Similarly, Dopa synthesis by control, secretin-stimulated (100 nM), or VIP-stimulated (2 $\mu \mathrm{M})$ irises was the same in standard and in calcium-free media (data not shown).

These data suggest that secretin and VIP stimulate TH activity in the submaxillary gland and iris by acting directly on sympathetic nerve terminals rather than indirectly via the calciumdependent release of another extracellular signal (e.g., from parasympathetic nerve terminals or parenchymal cells). The data further suggest that the stimulation of Dopa synthesis in the submaxillary gland by secretin or VIP does not rely on the entry of calcium into sympathetic nerve terminals. In contrast, calcium influx has been proposed to be necessary for TH activation by nicotinic agonists or potassium depolarization in the decentralized SCG (Ip et al., 1983, 1985; Rittenhouse et al., 1988).

\section{cAMP pathway also leads to stimulation}

Secretin and VIP elevate cAMP levels in many tissues (Mutt, 1983), including the rat SCG. In the latter, the increases in cAMP appear to trigger the activation of TH (Ip et al., 1985). In adrenergic nerve terminals, regulation of cAMP concentration may also play an important role in the regulation of $\mathrm{TH}$ activity by secretin and VIP. However, due to the small contribution by sympathetic nerve endings to the total tissue mass in autonomic end organs, effects of peptides on the total cAMP content of,

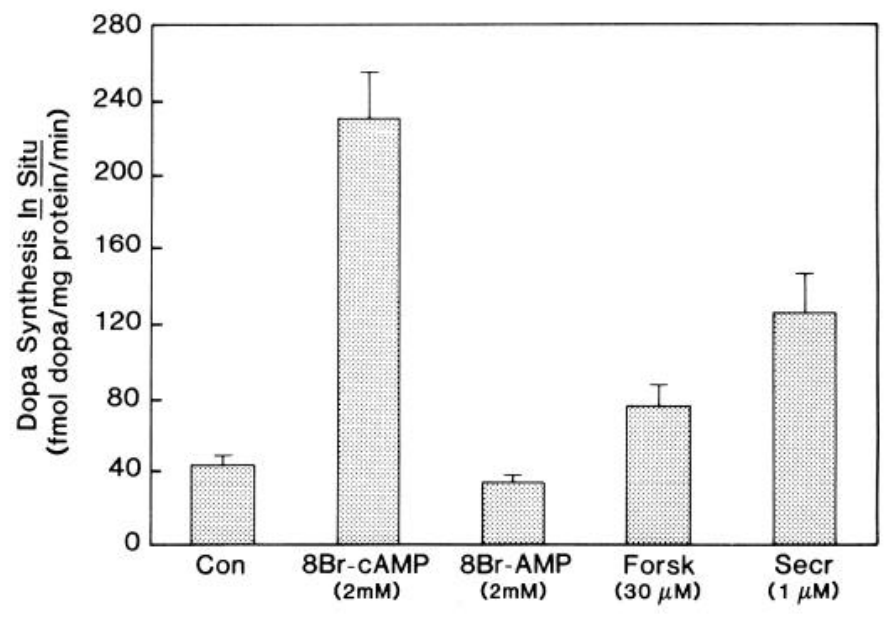

Figure 6. Effects of 8-Br-cAMP and forskolin on Dopa synthesis. Slices of submaxillary gland were incubated in medium containing brocresine, $1 \mathrm{mg} / \mathrm{ml} \mathrm{BSA}$, EDTA, and aprotinin, with or without 8-Br-cAMP, 8-Br-AMP, forskolin, or secretin. Each value represents the mean for 4 submaxillary gland slices.

for example, the submaxillary gland would be impossible to interpret with respect to cAMP changes within sympathetic nerve terminals. Nevertheless, supporting evidence that cAMP may be a second messenger for $\mathrm{TH}$ regulation in sympathetic nerve terminals comes from the findings that 8 -Br-cAMP, a hydrolysis resistant analog of cAMP, and forskolin, an activator of adenylate cyclase, both stimulated Dopa synthesis in submaxillary gland slices (Fig. 6). 8-Br-cAMP (2 mm) stimulated Dopa synthesis 5.6-fold, while its noncyclic analog, 8-Br-AMP (2 or 10 $\mathrm{mm}$; data not shown for the latter concentration), produced no effect. Forskolin $(30 \mu \mathrm{M})$ also stimulated Dopa synthesis in the submaxillary slice, though to a lesser extent (1.8-fold). In addition, in the iris, forskolin $(10 \mu \mathrm{M})$ stimulated Dopa synthesis in situ 4.4-fold (210 \pm 30 and $920 \pm 90 \mathrm{fmol} \mathrm{Dopa} / \mathrm{mg}$ protein/ min for the control and forskolin groups, respectively). An analog of cAMP has previously been shown to increase TH activity acutely in the guinea pig vas deferens (Weiner et al., 1978), another end organ innervated by sympathetic nerve fibers. However, since this tissue contains the cell bodies, as well as the terminals, of postganglionic sympathetic neurons (Ferry, 1967), it is unclear whether cAMP regulates TH activity in nerve terminals in the vas deferens.

\section{Distribution of the peptidergic mechanism in sympathetic neurons}

According to "Dale's principle," a neuron releases the same neurotransmitter(s) at all of its release sites. Dale's ideas concerning the metabolic homogeneity of the neuron led him to propose this hypothesis in 1934 (Potter et al., 1981; Eccles, 1986), and several findings have lent support to it over the years (e.g., Eccles et al., 1954; Furshpan et al., 1976; Otsuka and Konishi, 1983; Sombati and Hoyle, 1984). To what extent does this concept of metabolic homogeneity extend to the distribution of neurotransmitter receptors and signal transduction mechanisms in the various regions of a neuron? Although the answer is not yet clear, in the case of sympathetic neurons, muscarinic and adrenergic receptors appear to be located not only on their cell bodies and dendrites in sympathetic ganglia but also on their varicosities in various autonomic end organs (Brown et al., 1980; Brown and Caulfield, 1981; Langer and 
Hicks, 1984). Our results support the possibility that, in addition, a receptor(s) for secretin and VIP is present and coupled to the regulation of neurotransmitter metabolism in both the cell body and axon terminal regions of sympathetic neurons.

The data also demonstrate that different functional subclasses of postganglionic sympathetic neurons in the SCG (e.g., those that control the iris, salivary glands, and pineal gland) respond similarly to these neuropeptides. Furthermore, preliminary observations show that secretin and VIP stimulate TH activity in sympathetic ganglia other than the SCG (i.e., thoracic paravertebral ganglia) and in an autonomic end organ innervated by other ganglia (i.e., the heart) (H. Chiou, M. Schwarzschild, and R. Zigmond, unpublished observations). Thus, this peptidergic mechanism appears to be widely distributed between different types of sympathetic neurons, as well as between different regions of the sympathetic neuron.

\section{A possible role for endogenous peptides}

How would these peptidergic receptors be activated physiologically in autonomic end organs? At least 3 possiblc sources for released peptides exist: (1) endocrine glands via the circulation, (2) the sympathetic neurons themselves, and (3) nearby parasympathetic or sensory neurons. Plasma levels of secretin and VIP in mammals are generally in the low picomolar range (Burhol and Waldum, 1978; Said, 1982), and thus are far below concentrations required to stimulate $\mathrm{TH}$ activity in sympathetic neurons. While neural processes containing VIP-like immunoreactivity (VIP-IR) and PHI-IR are present in the SCG, only a small number of immunoreactive principal neurons have been observed (Sasek et al., 1987).

Peptides of the secretin-glucagon family have, however, been found in a number of autonomic end organs. VIP-IR and PHIIR appear to be contained primarily, if not exclusively, in varicosities of parasympathetic neurons. Thus, these immunoreactivities have been identified by radioimmunoassay and immunohistochemistry in the cat submaxillary gland (Lundberg et al., 1984a), where VIP-IR has been localized to acetylcholinesterase-rich neuronal cell bodies (Lundberg et al., 1979) and nerve terminals containing small agranular vesicles, which are characteristic of cholinergic neurons (Johansson and Lundberg, 1981). Stimulation of the parasympathetic input to this salivary gland releases VIP-IR and PHI-IR as well as ACh into the bloodstream (Lundberg et al., 1982, 1984b). In the rat also, high levels of VIP-IR occur in the submaxillary glands (Ekström et al., 1984). VIP-IR nerve fibers, though sparse, have been located within the rat iris (Björklund et al., 1985a). While VIP-IR was not detected immunohistochemically in the rat pineal gland, it has been identified in the pineal glands of several other mammalian species (Uddman et al., 1980). Secretin-like immunoreactivity has not as yet been reported in peripheral neurons. Interestingly, however, the concentration of secretin-like immunoreactivity measured by radioimmunoassay in the rat pineal gland exceeds that in the duodenum and in all brain regions tested (O’Donohue et al., 1981).

Generally, presynaptic receptors on sympathetic nerve terminals have been viewed as functioning to modulate the amount of neurotransmitter released by incoming action potentials (Langer and Hicks, 1984). Studies on NE release in autonomic end organs have suggested that, in certain cases, a transmittcr released by terminals of parasympathetic neurons influences nearby sympathetic nerve terminals. For example, in the heart, $\mathrm{ACh}$ released during parasympathetic nerve stimulation can diminish the release of NE during subsequent sympathetic nerve stimulation (Muscholl, 1982). The present findings demonstrate that presynaptic receptors on sympathetic nerve terminals may also be involved in the regulation of neurotransmitter synthesis. Furthermore, the stimulation of TH activity in sympathetic nerve terminals by VIP raises the possibility of a local interaction between the 2 major branches of the autonomic nervous system, leading to a regulation of NE biosynthesis.

\section{References}

Bhoola, K. D., and G. Dorey (1971) Kallikrein, trypsin-like proteases and amylase in mammalian submaxillary glands. Br. J. Pharmacol. 43: 784-793.

Birch, P. J., and M. Fillenz (1986a) Muscarinic receptor activation inhibits both the release and synthesis of noradrenaline in rat hippocampal synaptosomes. Neurochem. Int. 8: 171-177.

Birch, P. J., and M. Fillenz (1986b) Adenosine receptor and betaadrenoreceptor stimulation increases noradrenaline synthesis in hippocampal synaptosomes. Neurochem. Int. 8: 165-170.

Björklund, H., J. Fahrenkrug, Å. Seiger, J.-J. Vanderhaeghen, and L. Olson (1985a) On the origin and distribution of vasoactive intestinal polypeptide-, peptide HI-, and cholecystokinin-like-immunoreactive nerve fibers in the rat iris. Cell Tissue Res. 242: 1-7.

Björklund, H., T. Hökfelt, M. Goldstein, L. Terenius, and L. Olson (1985b) Appearance of the noradrenergic markers tyrosine hydroxylase and neuropeptide $Y$ in cholinergic nerves of the iris following sympathectomy. J. Neurosci. 5: 1633-1643.

Bowers, C. W., L. M. Dahm, and R. E. Zigmond (1984) The number and distribution of sympathetic neurons that innervate the rat pineal gland. Neuroscience 13: 87-96.

Brown, D. A., and M. P. Caulfield (1981) Adrenoreceptors in ganglia. In Adrenoreceptors and Catecholamine Action, G. Kunos, ed., pp. 99115, Wiley, New York.

Brown, D. A., S. Fatherazi, J. Garthwaite, and R. D. White (1980) Muscarinic receptors in rat sympathetic ganglia. Br. J. Pharmacol. 70: 577-592.

Burhol, P. G., and H. L. Waldum (1978) Radioimmunoassay of secretin in acidified plasma. Acta Hepato-Gastroenterol. 25: 474-481.

Dornay, M., V. H. Gilad, and G. M. Gilad (1985) Compensatory changes in contralateral sympathetic neurons of the superior cervical ganglion and in their terminals in the pineal gland following unilateral ganglionectomy. J. Neurosci. 5: 1522-1526.

Douglas, W., and A. M. Poisner (1963) The influence of calcium on the secretory response of the submaxillary gland to acetylcholine or to noradrenaline. J. Physiol. (Lond.) 165: 528-541.

Eccles, J. C. (1986) Chemical transmission and Dale's principle. Prog. Brain Res. 68: 3-13.

Eccles, J. C., P. Fatt, and K. Koketsu (1954) Cholinergic and inhibitory synapses in a pathway from motor-axon collaterals to motoneurones. J. Physiol. (Lond.) 126: 524-562.

Ekström, J., E. Brodin, R. Ekman, R. Håkanson, and F. Sundler (1984) Vasoactive intestinal peptide and substance $P$ in salivary glands of the rat following denervation or duct ligation. Regul. Peptides 10:110.

El Mestikawy, S., S. Bourgoin, F. Artaud, and M. Hamon (1981) In vitro and in vivo activation of tryptophan hydroxylase in the rat brain. In Function and Regulation of Monoamine Enzymes, E. Usdin, N. Weiner, and M. Youdim, eds., pp. 175-185, Macmillan, London.

Fahrenkrug, J., T. Bek, J. M. Lundberg, and T. Hökfelt (1985) VIP and PHI in cat neurons: Co-localization but variable tissue content possible due to differential processing. Regul. Peptides $12: 21-34$.

Ferry, C. B. (1967) The innervation of the vas deferens of the guineapig. J. Physiol. (Lond.) 192: 463-478.

Furshpan, E. J., P. R. MacLeish, P. H. O'Lague, and D. D. Potter (1976) Chemical transmission between rat sympathetic neurons and cardiac myocytes developing in microcultures: Evidence for cholinergic, adrenergic, and dual-function neurons. Proc. Natl. Acad. Sci. USA 73: $4225-4229$.

Ip, N. Y., C. K. Ho, and R. E. Zigmond (1982a) Secretin and vasoactive intestinal peptide acutely increase tyrosine 3-monooxygenase in the rat superior cervical ganglion. Proc. Natl. Acad. Sci. USA 79: 75667569 .

Ip, N. Y., R. L. Perlman, and R. E. Zigmond (1982b) Both nicotinic and muscarinic agonists acutely increase tyrosine 3-monooxygenase 
activity in the superior cervical ganglion. J. Pharmacol. Exp. Ther. 223: $280-283$

Ip, N. Y., R. L. Perlman, and R. E. Zigmond (1983) Acute transsynaptic regulation of tyrosine 3-monooxygenase activity in the rat superior cervical ganglion: Evidence for both cholinergic and noncholinergic mechanisms. Proc. Natl. Acad. Sci. USA 80: 2081-2085.

Ip, N. Y., C. Baldwin, and R. E. Zigmond (1984) Acute stimulation of ganglionic tyrosine hydroxylase activity by secretin, VIP and PHI. Peptides 5: 309-312.

Ip, N. Y., C. Baldwin, and R. E. Zigmond (1985) Regulation of the concentration of adenosine $3^{\prime}, 5^{\prime}$-cyclic monophosphate and the activity of tyrosine hydroxylase in the rat superior cervical ganglion by three neuropeptides of the secretin family. J. Neurosci. 5: 1947-1954.

Johansson, O., and J. M. Lundberg (1981) Ultrastructural localization of VIP-like immunoreactivity in large dense-core vesicles of 'cholinergic-type' nerve terminals in cat exocrine glands. Neuroscience 6: $847-862$.

Kilpatrick, I. C., M. W. Jones, and O. T. Phillipson (1986) A semiautomated analysis method for catecholamines, indoleamines, and some prominent metabolites in microdissected regions of the nervous system: An isocratic IIPLC technique employing coulometric detection and minimal sample preparation. J. Neurochem. 46:1865-1876.

Langer, S. Z., and P. E. Hicks (1984) Physiology of the sympathetic nerve ending. Br. J. Anaesthesiol. 56: 689-700.

Levitt, M., S. Spector, A. Sjoerdsma, and S. Udenfriend (1965) Elucidation of the rate-limiting step in norepinephrine biosynthesis in the perfused guinea-pig heart. J. Pharmacol. Exp. Ther. 148: 1-7.

Lowry, O. H., N. J. Rosebrough, A. L. Farr, and R. J. Randall (1951) Protein measurement with the Folin phenol reagent. J. Biol. Chem. 193: 265-275.

Lundberg, J. M. (1981) Evidence for coexistence of vasoactive intestinal polypeptide (VIP) and acetylcholine in neurons of cat exocrine glands. Morphological, biochemical and functional studies. Acta Physiol. Scand. (Suppl.) 496: 1-57.

Lundberg, J. M., T. Hökfelt, M. Schultzberg, K. Uvnäs-Wallensten, C. Köhler, and S. I. Said (1979) Occurrence of vasoactive intestinal polypeptide (VIP)-like immunoreactivity in certain cholinergic neurons of the cat: Evidence from combined immunohistochemistry and acetylcholinesterase staining. Neuroscience 4: 1539-1559.

Lundberg, J. M., A. Änggård, J. Fahrenkrug, G. Lundgren, and B. Holmstedt (1982) Corelease of VIP and acetylcholine in relation to blood flow and salivary secretion in cat submandibular salivary gland. Acta Physiol. Scand. 115: 525-528.

Lundberg, J. M., J. Fahrenkrug, T. Hökfelt, C.-R. Martling, O. Larsson, K. Tatemoto, and A. Änggård (1984a) Co-existence of peptide HI (PHI) and VIP in nerves regulating blood flow and bronchial smooth muscle tone in various mammals including man. Peptides 5: 593606.

Lundbcrg, J. M., J. Fahrenkrug, O. Larsson, and A. Änggård (1984b) Corelease of vasoactive intestinal polypeptide and peptide histidine isoleucine in relation to atropine-resistant vasodilation in cat submandibular salivary gland. Neurosci. Lett. 52: 37-42.

Malhotra, R. K., and A. R. Wakade (1987) Vasoactive intestinal polypeptide stimulates the secretion of catecholamines from the rat adrenal gland. J. Physiol. (Lond.) 388: 285-294.

Muscholl, E. (1982) Peripheral muscarinic control of norepinephrine release in the cardiovascular system. In Excitation and Neural Control of the Heart, M. N. Levy and M. Vassalle, eds., pp. 227-241, American Physiology Society, Bethesda, MD.
Mutt, V. (1983) VIP, motilin, and secretin. In Brain Peptides. D. T. Krieger, M. J. Brownstein, and J. B. Martin, eds., pp. 871-901, Wiley, New York.

Mutt, V., and S. I. Said (1974) Structure of the porcine vasoactive intestinal octacosapeptide. The amino-acid sequence. Use of kallikrein in its determination. Eur. J. Biochem. 42: 581-589.

Nishizawa, M., Y. Hayakawa, N. Yanaihara, and II. Okamoto (1985) Nucleotide sequence divergence and functional constraint in VIP precursor mRNA evolution between human and rat. FEBS Lett. 183: $55-59$.

O'Donohue, T. L., C. G. Charlton, R. L. Miller, G. Boden, and D. M. Jacobowitz (1981) Identification, characterization, and distribution of secretin immunoreactivity in rat and pig brain. Proc. Natl. Acad. Sci. USA 78: 5221-5224.

Otsuka, M., and S. Konishi (1983) Substance P-the first peptide neurotransmitter? Trends Neurosci. 6: 317-320.

Potter, D. D., E. J. Furshpan, and S. C. Landis (1981) Multipletransmitter status and "Dale's Principle." Neurosci. Comment. 1: $1-9$.

Rittenhouse, A. R., M. A. Schwarzschild, and R. E. Zigmond (1988) Both synaptic and antidromic stimulation of neurons in the rat superior cervical ganglion acutely increase tyrosine hydroxylase activity. Neuroscience 25: 207-215.

Said, S. I. (1982) Vasoactive Intestinal Peptide, pp. 447-468, Raven, New York.

Sasek, C. A., S. Landis, and R. E. Zigmond (1987) The distribution and possible cellular origins of vasoactive intestinal peptide and peptide histidine isoleucine amide in the rat superior cervical ganglion. Soc. Neurosci. Abstracts 13: 1337.

Schwarzschild, M. A., J. Rivier, W. W. Vale, N. Y. Ip, and R. E. Zigmond (1985) Activation of tyrosine hydroxylase in the rat superior cervical ganglion by peptides of the glucagon-secretin family. Soc. Neurosci. Abstr. 11: 1203.

Skok, V. I. (1973) Physiology of Autonomic Ganglia, pp. 17-24, Igaku Shoin, Tokyo.

Sombati, S., and G. Hoyle (1984) Glutaminergic central nervous transmission in locusts. J. Neurobiol. 15: 507-516.

Thoenen, H., U. Otten, and M. Schwab (1979) Orthograde and retrograde signals for the regulation of neuronal gene expression: The peripheral sympathetic nervous system as a model. In The Neurosciences: Fourth Study Program, F. O. Schmitt and F. G. Worden, eds., pp. 911-928, MIT Press, Cambridge, MA.

Tuček, S. (1985) Regulation of acetylcholine synthesis in the brain. J. Neurochem. 44: 11-24.

Uddman, R., J. Alumets, R. Håkanson, I. Lorén, and F. Sundler (1980) Vasoactive intestinal peptide (VIP) occurs in nerves of the pineal gland. Experientia 36: 1119-1120.

Weiner, N., F.-L. Lee, E. Dreyer, and E. Barnes (1978) The activation of tyrosine hydroxylase in noradrenergic neurons during acute nerve stimulation. Life. Sci. 22: 1197-1215.

Yau, W. M., J. A. Dorsett, and M. L. Youther (1986) Calcium-dependent stimulation of acetylcholine release by substance $P$ and vasoactive intestinal polypeptide. Eur. J. Pharmacol. 120: 241-243.

Zigmond, R. E. (1985) Biochemical consequences of synaptic stimulation: The regulation of tyrosine hydroxylase activity by multiple transmitters. Trends Neurosci. 8: 63-69. 